\title{
Modeling and Simulation of a Distributed Power System for Avionic Application
}

\author{
S. Vesti, P. Alou, J.A. Oliver, O. Garcia, R. Prieto and J.A. Cobos \\ Centro de Electrónica Industrial (CEI) \\ Escuela Técnica Superior de Ingenieros Industriales \\ Universidad Politécnica de Madrid \\ José Gutierrez Abascal 2, Madrid, Spain \\ Tel.: +34913363191 Fax: +34915645966
}

\begin{abstract}
This paper describes design and analysis method for a DC distributed power system for Avionic Application utilizing simulation. In order to obtain rapid time to market, the used system components are typically commercial off-the-shelf components (COTS). This complicates the system level analysis and simulation because traditional modeling methods are not applicable. Within this paper, it is shown how these systems can be designed utilizing simulation results based on behavioral models of commercial dc/dc converters. Additionally, models for commercial EMI filters are developed. From the system level simulations important information of the whole system behaviour, such as power consumption, and overall stability is oblained. This assists the designer to reach an optimum power system solution with minimum time and effort. Therefore, the system level simulation is an essential tool for reaching the feasible design solution complying with all the recpuirements'.
\end{abstract}

\section{INTRODUCTION}

Distributed power systems comprise various different commercial components and can be very complex in nature. Moreover, simulation and analysis of these systems is challenging due to the lack of detailed information of the component structures. Thus concerning the system level simulation, it is desirable to develop models for the conmercial components.

Power system stability can be analysed as sinall signal stability, interactions between input filter and $\mathrm{dc} / \mathrm{dc}$ converter as shown in [1] and [2], or large signal stability due to converter turn-on/off delays, start-up and protections. Therefore, a dc-dc converter model is required to be applicable in the analysis of both sinall and large signal stability.

Plenty of research concerning the dc/dc converter modeling techniques exists. General averaged model for the converter has been developed in [3] and been applied to distributed power system simulations in [4]. Additionally, in [5] and [6] is described how to oblain hybrid paraneter models which are limited to analyse sinall signal stability. However, neither of the above mentioned models is adequate to analyse large signal stability. Thus, an improved $\mathrm{dc} / \mathrm{dc}$ converter model is required.

\footnotetext{
${ }^{1}$ This project has been supported by Indra.
}

In [7] and [8] behavioral model for dc-dc converter is developed based on the Wiener-Hannerstein structure. Thus enabling adequate DC distributed power system simulations as presented in [9]. In [9] a parameterization software tool is developed to generate the behavioral models and the requirements for the simulator are described in [10].

In this paper a distributed power system for avionic application is designed according to the requirements provided in [11] concerning the Aircraft Electric Power Characteristics and [12] regarding Electromagnetic interference characteristics. The system consists of six dc-dc converters supplying the loads according to their demands from few watts until $65 \mathrm{~W}$. As one important objective of avionic application is to minimize the size and weight of the system, the optinum solution was to select converters from various manufacturers. Due to the tight EMC requirements stated in [12], additional EMI filters are used within the system. In the cunrent system, a distributed EMI filter solution was selected utilizing the EMI filters recommended by the converter manufacturer. Thus the system includes four EMI filters as well as holdup capacitors and protection circuits as shown in Figure 1.

The utilized dc-dc converter models are based on the Wiener-Hanmerstein structure and their modeling procedure is described and analyzed in detail. In addition, EMI filter models for the conmercial filters are developed based on typical input filter structure [13] and impedance measurements. The sinall signal stability is observed assessing the interactions between EMI filter and a dc/dc converter. Based on the created component models, the system behavior is analyzed through simulations and the are validated through experimental results.

\section{SYSTEM COMPONENT MODELING}

The most important system components, dc-dc converters and EMI filters, are modeled in order to successfully simulate the system behavior. 


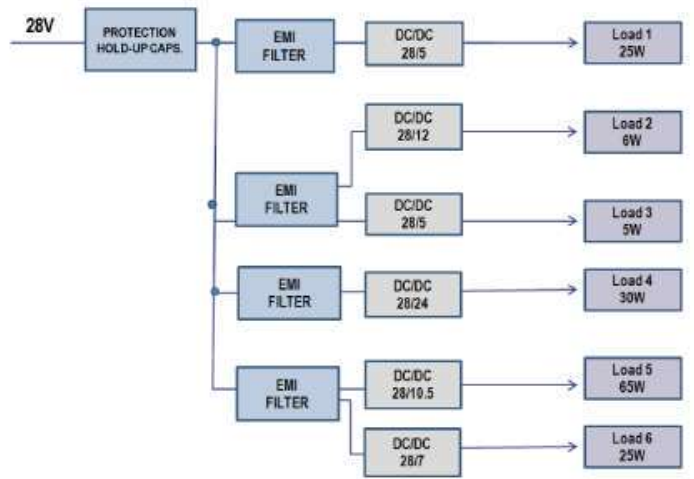

Fig. 1. Distributed power system block diagram.

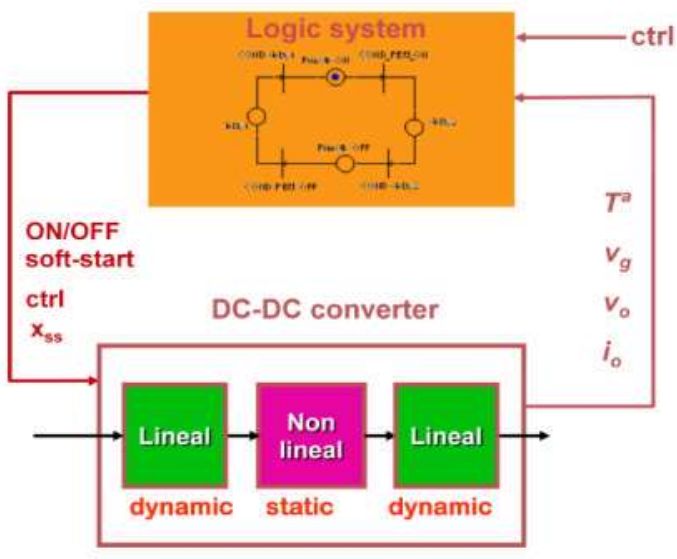

Fig. 2. Dc-dc converter behavior model structure.

\section{A. Dc-dc converter models}

As the objective is to model commercial converters, utilized model for the dc-dc converters is required to be identified based on available information. In addition, this model needs to be general for every dc-dc converter, regardless of the utilized topology or implemented control method. The utilized model for the converters consists of two parts, logic stage and power stage based on Wiener-Hammerstein structure [8] as presented in Figure 2.

Events driven behavior is modeled as a logic system whereas the Wiener-Hammerstein structure describes the static and dynamic behavior of the converter and its control. This behavior model can be generated from the parameters obtained from the converter datasheet. Thereafter, it can be implemented to a circuit simulator [14] utilizing hardware description language. The following information is required in order to obtain simulation models for the dc-dc converters based on this modeling technique:

- Static behavior: Output voltage dependence on the load

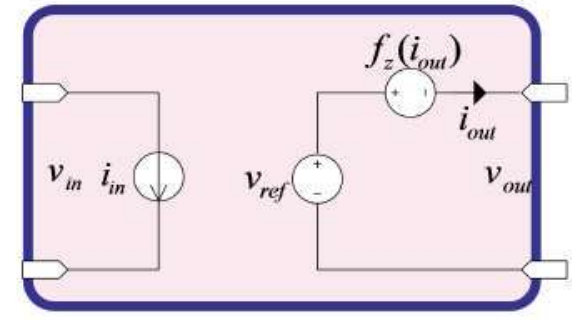

Fig. 3. The static model structure of a Dc-dc converter.

current and input voltage, as well as efficiency dependence on the load current and input voltage.

- Dynamic behavior: Inrush current and output voltage transient response.

- Events driven behavior: Protections, soft start and remote control.

Every $\mathrm{dc} / \mathrm{dc}$ converter utilized within the system was modeled based on the information provided in the datasheet and obtained from the measurements. The model validation was done by comparing simulation results to the datasheet curves provided by the manufacturer.

1) Static structure: The static parameters describe the basic power processing behavior of a dc-dc converter. The static converter behavior is modeled as an equivalent circuit shown in Figure 3, where Equation 1 describes the load regulation and Equation 2 defines the efficiency dependence on the load current.

$$
\begin{gathered}
v_{\text {out }}=v_{\text {ref }}-f\left(i_{\text {iout }}\right) \\
i_{\text {in }}=\frac{1}{\eta\left(i_{\text {out }}\right)} \cdot \frac{v_{\text {out }} \cdot i_{\text {out }}}{v_{\text {in }}}
\end{gathered}
$$

The efficiency dependence on the converter output power illustrates the converter static behavior. In Figure 4 the efficiency curve of the created simulation model is compared to the corresponding datasheet value at nominal input voltage of $28 \mathrm{~V}$. The dashed line shows that the simulation model provides accurate results concerning the static behavior of a converter.

2) Dynamic structure: The dynamic information includes high frequency dynamics and large signal behavior to the converter model as presented in Figures 5.a and 5.b.

The component values for the input dynamic network can be obtained from the converter inrush current curve. Correspondingly, the component values for the output dynamic network are obtainable from the transient response behavior of the converter. 


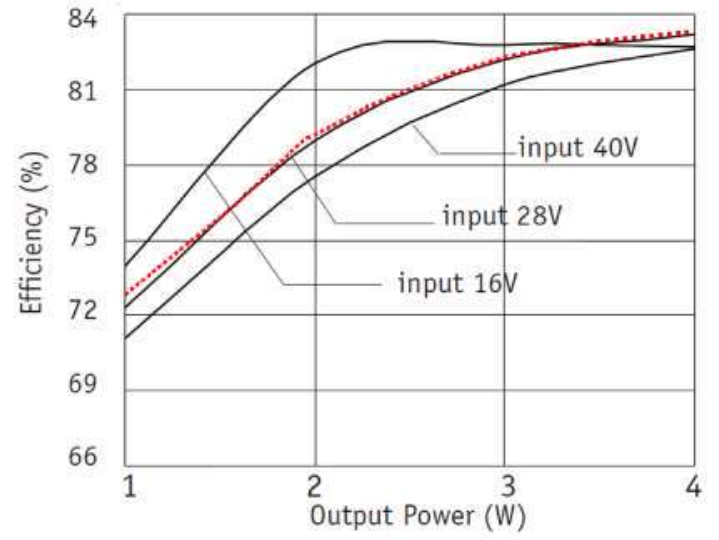

Fig. 4. The simulated efficiency as a function of output power compared to the datasheet value.

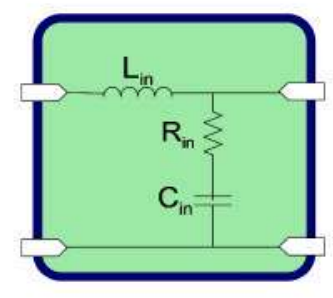

a)

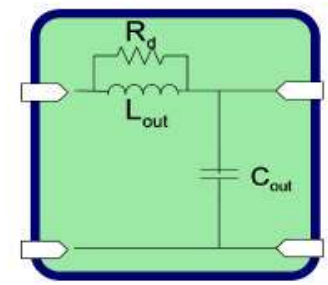

b)
Fig. 5. Equivalent EMI filter model structure. a) Input dynamics network. b) Output dynamics network.

3) Logic system: The system large signal stability is not possible to be predicted without including the converter protection features. The events driven behavior is essential to take into consideration within the converter model in order to provide accurate system analysis. Considering the actual model, the events driven behavior is managed by a state machine that changes the model structure.

Since converters from various manufacturers are utilized, each of them needs an individual model. Every converter model was validated concerning static, dynamic and events driven behavior thus guaranteeing proper behavior of the simulation models.

4) Improved Dc-dc converter models: The dc-dc converter models can be further improved by performing measurements to the converters. The datasheets typically provide limited amount of information concerning specific converter behavior. Thus depending on the application some relevant and more detailed information might be required in order to perform accurate system level simulations. Therefore, further measurements assist the improvement of the converter models.

The existing dc-dc converter model does not take into consideration audiosusceptibility. This means that depending on the converter topology and implemented control method,

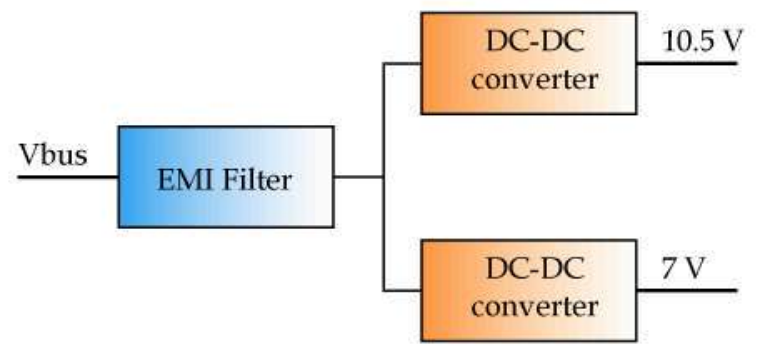

Fig. 6. Shared EMI filter configuration.

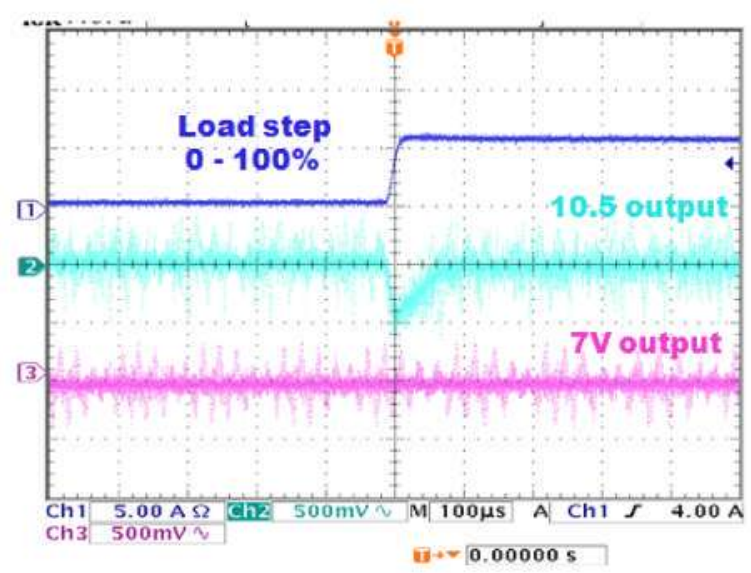

Fig. 7. Audiosusceptibility measurement.

sudden input voltage drop might cause deviation on the converter steady state output voltage. Within the designed system this might occur when a load step is introduced to a converter sharing an EMI filter as shown in Figure 6.

As the two converters have common input voltage, it is of interest to verify audiosusceptibility through measurement. Thus it can be decided whether audiosusceptibility is necessary to be included within the converter model.

The measurement was carried out by introducing a load step from no load to full load on the output of $10.5 \mathrm{~V}$ power module while the output voltage of the $7 \mathrm{~V}$ module was observed. The measurement results show, Figure 7 , that in this particular case the audiosusceptibility is not necessary to be taken into consideration regarding the analyzed converter.

\section{B. EMI Filter Models}

The proposed models for the commercial EMI filters are based on the general topological structure of an input filter [13]. In order to estimate these component values, the frequency response of each filter was measured. The following measurements were carried out:

- Short circuit input impedance while output is shortcircuited 


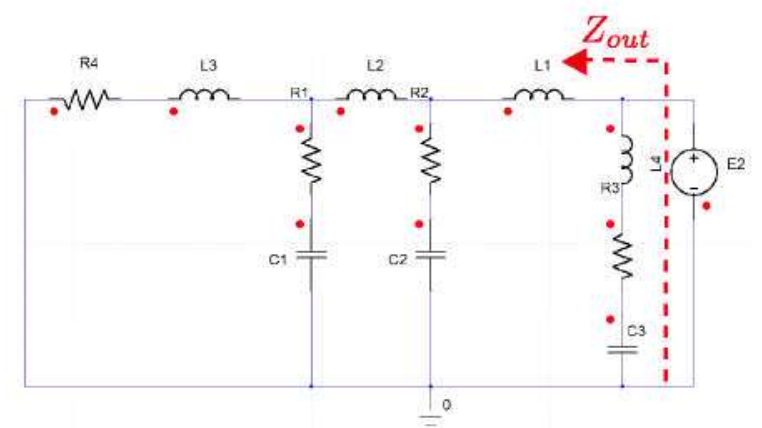

Fig. 8. Equivalent EMI filter model structure and output impedance simulation.

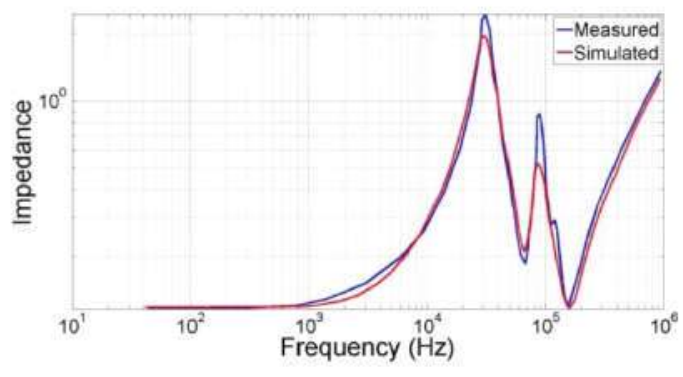

Fig. 9. Simulated and measured output impedances.

- Open circuit input impedance while output is open circuit

- Output impedance while input is short-circuited

The best suitable model for each EMI filter was obtained by fitting simulated ac responses to the measured ones. In addition to the basic filter components, the parasitic values are needed to take into consideration due to their affect on the ac response at high frequencies. Utilizing this principle, models for each commercial filter were obtained. An equivalent circuit and output impedance simulation of one input filter topology is presented in Figure 8.

As the system design is based on distributed EMI filter solution, various filters from different manufacturers are used and each filter has its own equivalent circuit. Figure 9 presents the comparison of simulated output impedance value compared to measured value of the equivalent circuit presented in Figure 8.

Based on the results presented in Figure 9, the simulation models of the input filters can be assumed to provide adequate models for the utilized EMI filters in order to obtain necessary system level simulations.

\section{Stability analysis}

As stability is major concern within any power systems, it is desirable to detect any potential stability problems at an early design stage. Two types of instability problems, small

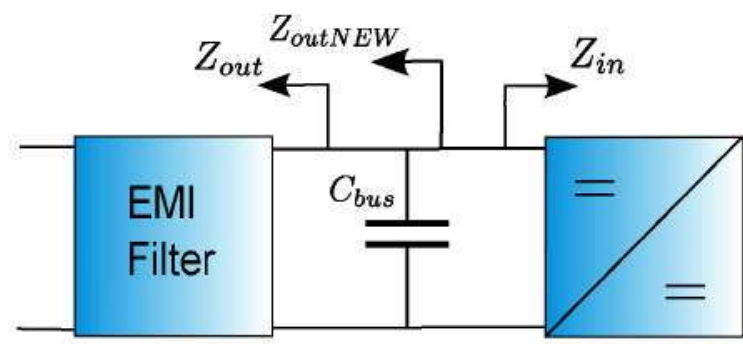

Fig. 10. Impedance interactions between input EMI filter and a $\mathrm{dc} / \mathrm{dc}$ converter.

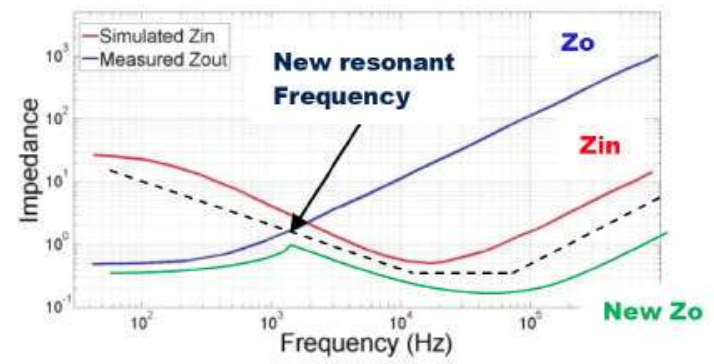

Fig. 11. Measured EMI filter Zout compared to the simulated converter Zin and suggested bus capacitor.

signal and large signal, can occur within distributed power systems. By utilizing the developed component models, the system stability can be analyzed from two different perspectives.

\section{A. Small signal stability}

Small signal instability can occur due to the impedance interactions between the input filter and a $\mathrm{dc} / \mathrm{dc}$ converter as presented in [2]. This Middlebrook's criterion for impedance inequalities is described in Equation 3.

$$
Z_{o}<<Z_{\text {in }}
$$

where $Z_{o}$ is the filter output impedance and $Z_{i n}$ is the converter input impedance as shown in Figure 10.

Utilizing the developed behavioral converter model, the input impedance is obtainable through simulation. Thus the simulated input impedance can be compared to the measured filter output impedance. Each converter input impedance as well as the corresponding filter output impedance was analysed. Based on this analysis, a possible instability problem was discovered, as demonstrated in Figure 11.

It can be observed that the Middlebrook criterion $Z_{o}<<Z_{\text {in }}$ is not met. This small signal instability problem can be eliminated by altering the filter output impedance by adding sufficiently capacitance at the filter output thus shifting the resonant frequency of the output impedance. In Figure 11 the dashed line presents bus capacitor impedance. 


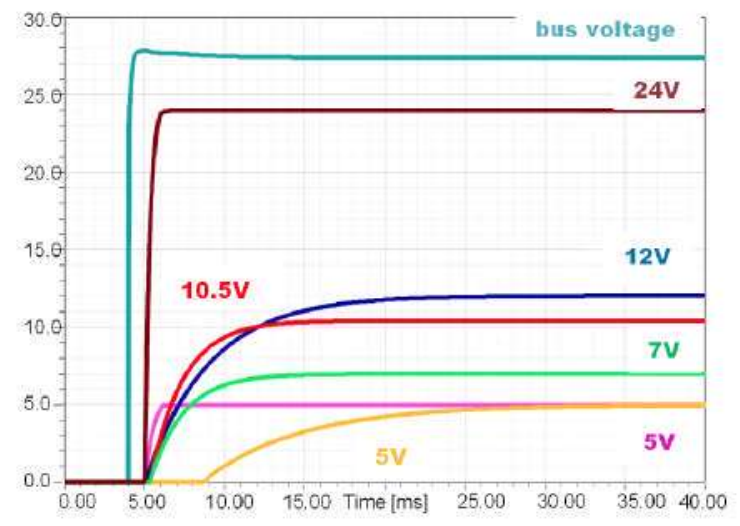

Fig. 12. The converter output voltages at the system start-up.

However, the selected capacitor is required to have low ESR and ESL values due to their impact on the capacitor impedance at high frequencies. The capacitor solution utilized within this design was to parallel four $22 \mathrm{uF}$ and 50V AVX multilayer capacitors employing low ESR and ESL values in order to avoid any instability within the system.

\section{B. Large signal stability}

Even though the individual input filter and dc-dc converter complies with the small signal stability criterion, the system level stability is not guaranteed. Large signal instability can occur at the system the level due to various reasons:

- Pulsating loads

- System start-up and turn-on delays

- Remote on/off signals

- Protections

Depending on the specific application, the above mentioned features might be necessary within a distributed power system. Each system employs different features and requirements. In addition, every converter has individual behavior and implemented additional features such as protections or ability to remote turn on/off. System level simulation is a necessary tool in order to confirm proper operation of the whole system under various operating conditions. Utilizing the developed dc-dc converter and EMI filter models described in Section two, the whole system can now be simulated. It is of interest to guarantee a stable system start-up under various operating conditions. Since the utilized converters within the system are from various manufacturers, they all employ different start-up behavior. The simulated start-up at the nominal operating conditions is shown in Figure 12.

As the simulated turn-on behavior of all converters is compared to the measurements, Figure 13, it can be observed that the simulations predict the system behavior accurately.

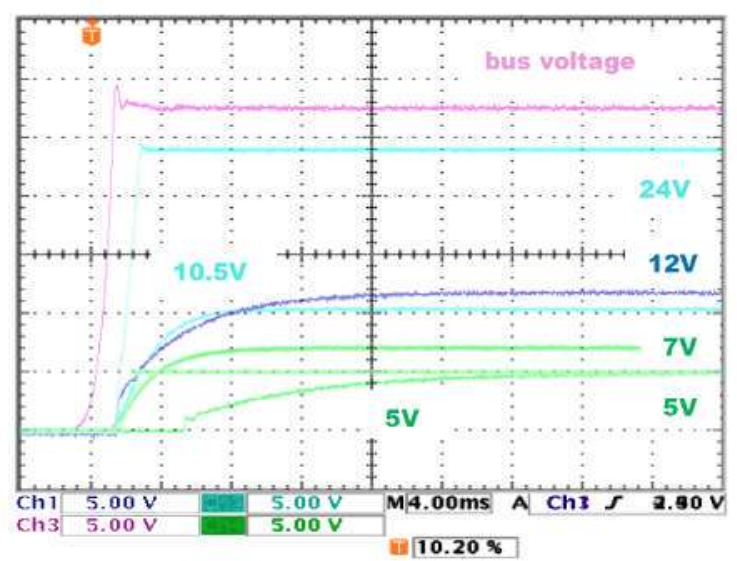

Fig. 13. The measured system start-up.

\section{SYSTEM FUNCTIONALITY VERIFICATION}

The power system operation has been analyzed through the following simulations, in addition to the start-up measurements described in the previous section:

- Inrush current

- Transient behavior

- General functionality during various operating conditions

\section{A. Inrush current}

The current absorbed by the system during the startup can be estimated though the system simulations. Each dc-dc converter has its own specified inrush current absorption depending on the converter structure. In addition, if the system is required to provide holdup time, the influence of large holdup capacitors to the system inrush current is significant. As system inrush current is simulated, depending on the application it can be determined whether any protection is necessary within the designed system. While simulating the inrush current, line impedance as well as parasitic component values of other circuit components should be taken into consideration, due to their affect on the inrush current. Within the actual system, inrush current protection was designed based on the system inrush current simulations. The simulated inrush current peak during the start-up is presented in Figure 14. Subsequent to implementing inrush current protection, the start-up was simulated. The protection was implemented to the current system and inrush current measurements are compared to the simulation results in Figure 15.

The simulated peak current value will not predict the exact behavior of the actual protection circuit. This is due to the implementation method of the inrush current protection model within the simulated system. Accurate protection circuit component models were not available for the utilized simulator and therefore, simplified component models were 


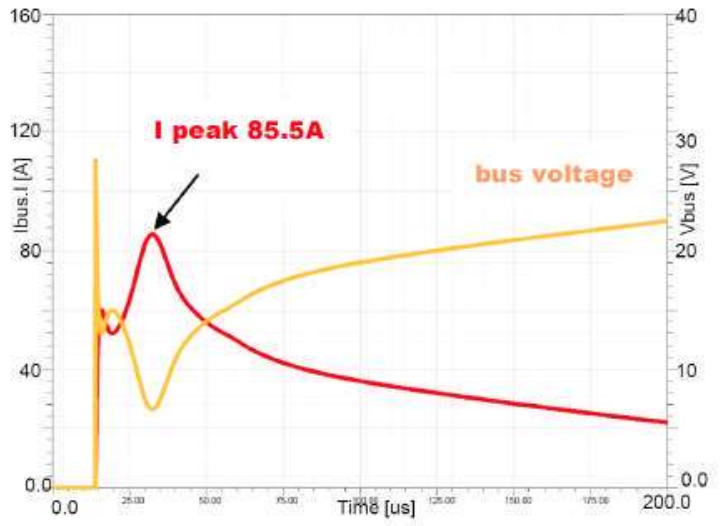

Fig. 14. The simulated input current and bus voltage during the start-up.

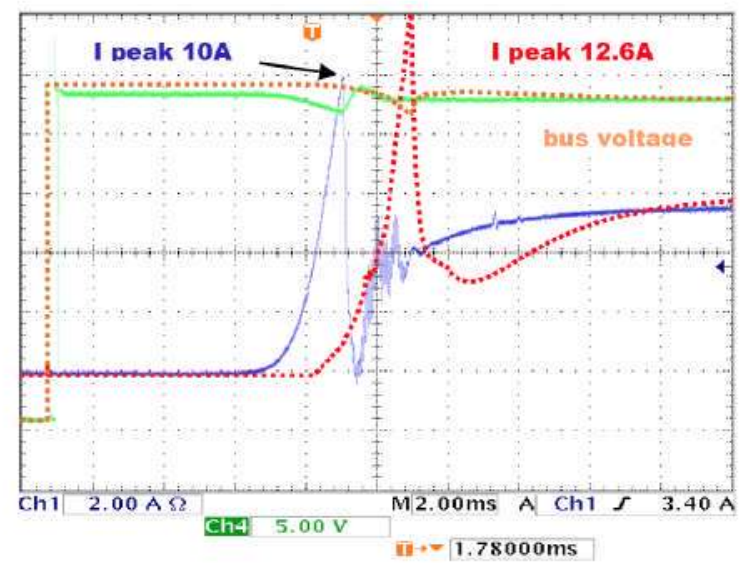

Fig. 15. Measured and simulated inrush current with the protection.

utilized. However, the results are adequate enough to verify the functionality of the designed inrush current protection.

\section{B. Transient behavior}

The system behavior under load transients can be analyzed through simulation. A load step from no load to full load was introduced to the largest power module $10.5 \mathrm{~V}$ output and its influence within the system was observed. The corresponding measurement was carried out within the system and compared to the simulation as shown in Figure 16. The dashed line shows the simulation result and subsequent to the comparison of measured value, it can be observed that the modeled dcdc converter predicts accurately the transient behavior of the actual converter.

Transient simulations provide valuable information on the converter ability to reach the output voltage steady state value. This is important in case the converter is supplying a pulsating load. In case the converter has not reached its steady state value and the load is changed, instabilities within the system might occur. Thus in order to avoid this from happening, additional capacitance is required to be added at the converter output to

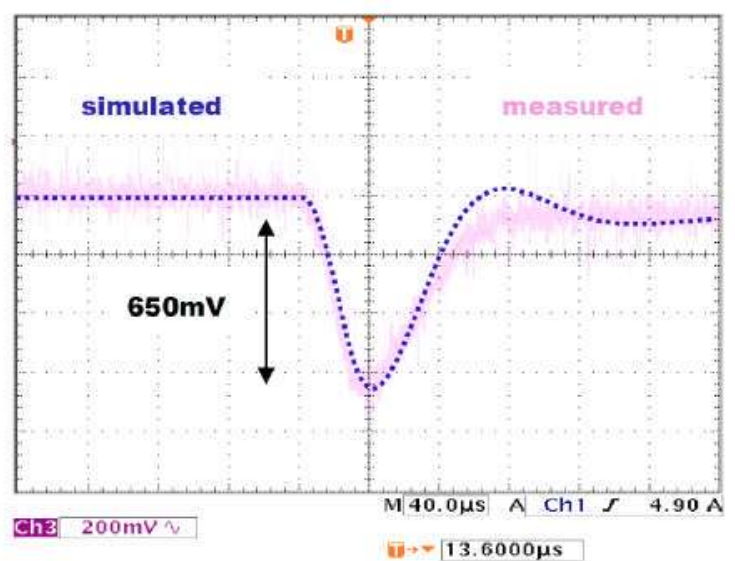

Fig. 16. Detailed comparison between measured and simulated (dashed line) voltage deviation in $10.5 \mathrm{~V}$ module during the load step.

provide energy. However, depending on the converter design, each power supply has a maximum allowable capacitive load which should be considered.

\section{General operational aspects}

Power consumption is an important aspect within any electronic design, especially in avionic power systems. It is of interest to be able to estimate it as early design state as possible. The power system within this application is required to operate within the nominal input voltage range of $22 \mathrm{Vdc}$ to $29 \mathrm{Vdc}$ according to [11] in steady state. Therefore, the system level simulations provide estimations of the system power consumption by determining the steady-state current absorbed by the system for various input voltages.

\section{CONCLUSION}

Due to the utilized COTS components within distributed power system design, traditional modeling techniques are not applicable. This introduces various problems within the system design complicating the overall analysis. The $\mathrm{dc} / \mathrm{dc}$ converters are modeled based on the Wiener-Hammerstein structure enabling the system simulation and analysis. A detailed modelling procedure is described for both dc-dc converters as for EMI filters. The theoretical system analysis and the simulated operation are verified in practise within designed distributed power system for avionic application. System small and large signal stability is analysed utilizing the simulation results obtained from the modeled system. A potential instability problem was discovered at the system design stage thus enabling to solve the problem prior to implementing the actual system. Within distributed power system design, system level simulation is a vital tool in order to reduce the design time. In addition, the ability to discover possible system instability problems or design errors at an early design stage is crucial in system design. 


\section{REFERENCES}

[1] N.O. Sokal. System oscillations from negative input resistance at power input port of switching-mode regulator, anplifier, $\mathrm{dc} / \mathrm{dc}$ converler, or defac inverter. pages $138-140,1973$.

[2] R.D. Middlebrook. Input filter considerations in design and application of switching regulators. pages $336-382,1976$.

[3] S.R. Sanders, J.M. Noworolski, X.Z. Liu, and G.C. Verohese. Generalized averaging method for power conversion circuits. Power Electronics. IEEE Transactions on, 6(2):333-340, apr 1991.

[4] A. Emadi. Modeling and analysis of multiconverter dc power electronic systems using the generalized state-space averaging method. Industrial Electronics, IEEE Transactions on, 51(3):661 - 668, june 2004.

[5] B.H. Cho and F.C.Y. Lee. Modeling and analysis of spacecraft power systems. pages $523-534,1985$.

[6] B.H. Cho and F.C.Y. Lee. Modeling and analysis of spacecraft power systems. Power Electronics, IEEE Transactions on, 3(1):41 -54, jan 1988.

[7] J.A. Oljver, R. Prieto, J.A. Cobos, O. Garcia, and P. Alou. Hybrid wiener-bammerstein structure for grey-box modeling of dc-dc conveners. In Applied Power Electronics Conference and Exposition. 2009. APEC 2009. Twenty-Fourth Amtial IEEE, pages 280-285, 15-19 2009.

[8] J.A. Oliver, R. Prieto, V. Ronero, and J.A. Cobos. Behavioral modeling of dc-dc converters for large-signal sinulation of disiributed power systems. In Applied Power Electronics Conference and Exposition. 2006 . APEC 'O6. Twenry-First Ammual IEEE, page 6 pp., 19-23 2006.

[9] R. Prieto, L. Laguna, J. Oliver, and J. Cobos. A parameterization tool for power electronics design at system level. In Power Electronics Congress, 2008. CIEP 2008. 11th IEEE Internotional, pages 210-214, 24-27 2008.

[10] J.A. Oliver, R. Prieto, L. Laguna, and J.A. Cobos. Modeling and simulation requirements for the analysis and design of dc distributed power electronic systems. In Power Electronics Congress, 2008. CIEP 2008. 11th IEEE International, pages 204 -209, 24-27 2008.

[11] Department of Defense Interface standard. Aircraft Electronic Power Characteristics, MIL-STD-704F. 2004.

[12] Department of Defense Interface standand. Requirements for the Control of Electromagnetic Interference Characteristics of Subsystems and Equipment, MIL-STD-f6IF. 2004

[13] Robert W. Erickson and Dragan Maksinovic. Fundainentals of power elecironics, second edition, 2000 .

[14] R. Prieto, L. Laguna, J.A. Oliver, and J.A. Cobos. Dc/dc converter paranetric nodels for system level sinulation. In Applied Power Electronics Conference and Exposition, 2009. APEC 2009. TwentrFourth Arrual lEEE, pages $292-297,15-192009$ 